\title{
Crescimento de mudas de pau viola (Cytharexyllum myrianthum) são poten- cializadas utilizando resíduos do tratamento de esgoto doméstico
}

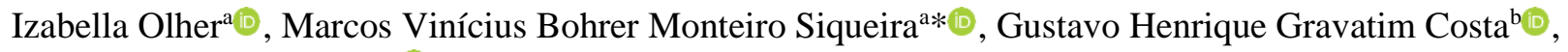 \\ Thomaz Figueiredo Lobo ${ }^{a} \odot$ \\ ${ }^{a}$ Universidade do Sagrado Coração, Brasil \\ ${ }^{\mathrm{b}}$ Universidade do Estado de Minas Gerais, Brasil \\ *Autor correspondente (mvbsiqueira@gmail.com)
}

\section{N F O}

\section{Keywords}

biosolid

seedling quality

substrates

seedling nursery

\begin{abstract}
A B S T R A C T
Growth of pau viola (Cytharexyllum myrianthum) seedlings are potentialized using waste from the treatment of domestic sewage.

Sewage sludge is a waste rich in organic matter and mineral nutrients generated at Sewage Treatment Stations. Generally, this waste is deposited in landfills, increasing the volume of disposal at the site, and therefore the levels of pollution. No less important, it is a material that is lost and could be reused as fertilizer for the forestry and agricultural sector. However, more studies are pertinent to make its use feasible, especially in nurseries that produce native seedlings. The objective of this work was to evaluate the development of pau viola (Cytharexyllum myrianthum), in relation to composted sewage sludge (LEC) and commercial substrate (SC), testing two types of water, waste and supply. The following biometric parameters were obtained: height, stem diameter and number of leaves, as well as dry matter production (root and aerial part). The results revealed that there was no significant difference between the treatments evaluated. Among the types of water, the wastewater seedlings developed more, obtaining seedlings with higher values of height, number of leaves, diameter of the root collar and dry matter of the leaves and root. To produce pau viola seedlings, it is advisable to use the combination of LEC and the use of wastewater for irrigation. We believed that following these recommendations there will be a reduction in nursery costs to the production of pau viola seedlings and a reduction in the disposal of this waste in the environment.
\end{abstract}

\section{R E S U M O}

O lodo de esgoto é um resíduo rico em matéria orgânica e nutrientes minerais gerado nas Estações de Tratamento de Esgoto. Geralmente este resíduo é depositado em aterros sanitários, aumentando o volume de descarte no local, e por conseguinte os níveis de poluição. Não menos importante, perde-se um material que pode ser reaproveitado como adubo para o setor florestal e agrícola. No entanto, é pertinente mais estudos que viabilizem o seu uso, sobretudo em viveiros produtores de mudas nativas. O objetivo desse trabalho foi avaliar o desenvolvimento do pau viola (Cytharexyllum myrianthum), em relação ao lodo de esgoto compostado (LEC) e substrato comercial (SC), testando-se dois tipos de água, residuária e de abastecimento. Foram obtidos os seguintes parâmetros biométricos: altura, diâmetro do coleto e número de folhas, bem como a produção de matéria seca (raiz e parte aérea). Os resultados revelaram que não houve diferença significativa entre os tratamentos avaliados. Entre os tipos de água, as mudas da água residuária se desenvolveram mais, obtendo mudas de maiores valores de altura, número de folhas, diâmetro do coleto e matéria seca das folhas e raiz. Para a produção de mudas de pau viola, é aconselhável a utilização da combinação de LEC e o uso de água residuária para a irrigação. Acredita-se que com estas medidas haverá redução dos custos dos viveiros para a produção de mudas e da disposição desses resíduos no meio ambiente. 


\section{INTRODUÇÃO}

A produção de mudas de espécies florestais é uma das etapas mais importantes do sistema produtivo, entretanto, é dependente de insumos, tornando o substrato indispensável devido à influência no enraizamento, retenção de água, nutrição e qualidade das mudas (Trazzi et al., 2013, 2014; Lustosa Filho et al., 2015). A necessidade de produção de mudas para plantios comerciais e recuperação de áreas degradadas tem promovido o desenvolvimento de tecnologias que envolvam a redução dos custos de manejo e que garantam um bom desenvolvimento em campo.

Dentre essas novas tecnologias, destacam-se a utilização de inúmeros resíduos que são reaproveitados de várias cadeias produtoras para o cultivo e geração de mudas nativas. Esses métodos, além de apresentarem vantagens socioambientais, também podem ser de baixo custo e com resultados nutricionais e fitossanitários importantes para diversas espécies florestais.

Neste contexto, o uso de lodo de esgoto compostado (LEC) vêm apresentando resultados positivos quando aplicado como substrato para a formação de mudas nativas (Trigueiro e Guerrini, 2014; Lobo et al., 2018). Esses benefícios ocorrem em razão do lodo ser rico em matéria orgânica, o que promove o incremento da fertilidade do solo, retenção de água e ciclagem dos nutrientes (Santos et al., 2014). Essas características o tornam uma alternativa economicamente viável, visto que seu uso diminui ou mesmo elimina a necessidade da aplicação de fertilizantes minerais, tornando o processo de formação de mudas mais sustentável, conservativo e econômico (Paez, 2011). Deve-se ressaltar que o processo de compostagem apresenta alta eficiência na eliminação de patógenos e gera um resíduo de alta qualidade agronômica, tornando o composto apto para o uso florestal (Santana et al., 2019), regulamentado pela Resolução CONAMA n ${ }^{\circ}$ 375/2006 (Brasil, 2006).

Além do uso do LEC, o uso de águas residuária é igualmente uma alternativa viável, sobretudo pela crescente escassez hídrica e ao elevado consumo de água nos viveiros florestais (Araújo et al., 2016; Rebouças et al., 2018). Segundo Cromer (1980), o reuso de águas na atividade florestal constitui um método seguro por não envolver produção de alimentos e nem riscos à saúde, além de ser uma forma de ampliar a disponibilidade, bem como conservar os recursos hídricos existentes (Freire et al., 2010).

Muitas pesquisas têm procurado compreender como o uso de LEC pode contribuir para os aspectos sociais, ambientais e agronômicos. Espécies como o dedaleiro (Lafoensia pacari A.St-Hil), quaresmeira (Tribouchina granulosa Cogn.) e embaúba (Cecropia hololeuca Miq.) tem sido alvo de sucesso desses estudos (Lobo et al. 2018; Santana et al., 2019; Morgado et al., 2020).

Neste cenário, ainda não há informações disponíveis de como a formação de mudas de pau viola (Citharexylum myrianthum Cham) ocorre se manejada com LEC e águas residuárias. Essa espécie tem sido muito utilizada em programas de recomposição de matas ciliares e com finalidades paisagísticas em praças e parques urbanos (Amaral et al., 2013), sendo que sua procura em viveiros especializados tem crescido significativamente. Deve-se destacar ainda que o pau de viola é nativo no país e tem ocorrência ampla no nordeste, sudeste e sul do Brasil, em formações de Cerrado, Caatinga e Mata Atlântica. É considerada uma espécie pioneira, apresentando ótima regeneração natural em vários estágios da sucessão secundária e produzindo anualmente uma grande quantidade de flores e frutos (Souza, 2014).

O objetivo do trabalho foi avaliar o desenvolvimento de mudas de pau viola cultivadas em substratos formados por LEC associado à irrigação com água residuária, originária da Estação de Tratamento de Esgoto de Bauru/SP.

\section{MATERIAL E MÉTODOS}

\section{Delineamento experimental}

O estudo foi realizado no viveiro de mudas ACIFLORA (Associação de Recuperação Florestal e Ecológica da Região de Bauru), localizado no município de Bauru. O delineamento experimental foi em parcelas subdivididas com 4 repetições. Os tratamentos principais foram compostos por 5 diferentes substratos, e os secundários compostos por dois tipos de água de irrigação (Tabela 1).

Tabela 1 - Composição dos tratamentos principais e secundários empregados no estudo.

\begin{tabular}{cc}
\hline $\begin{array}{c}\text { Tratamentos } \\
\text { Principais }\end{array}$ & Composição \\
\hline T1 & 100\% SC (Testemunha) \\
T2 & $83,29 \% \mathrm{SC}+16,71 \%$ LEC \\
T3 & $71,43 \% \mathrm{SC}+28,57 \%$ LEC \\
T4 & $62,5 \% \mathrm{SC}+37,5 \%$ LEC \\
T5 & $55,56 \% \mathrm{SC}+44,44 \% \mathrm{LEC}$ \\
\hline Tratamentos Se- & Composição \\
cundários & Água de abastecimento \\
L1 & da rede \\
L2 & Água residuária \\
\hline SC - Substrato Comercial Carolina Soil. LEC - Lodo de Esgoto Com- \\
postado.
\end{tabular}




\section{Caracterização do substrato e da água residuária utilizada}

O substrato comercial utilizado (SC) é amplamente utilizado por viveiristas para produção de mudas nativas, e que a composição entre SC e LEC (fornecido pela empresa Tera Ambiental) foi realizada em função do volume de substrato utilizado, considerando-se a composição química do LEC (Tabela 02).

Tabela 2 - Características químicas do lodo de esgoto compostado.

\begin{tabular}{|c|c|c|c|c|c|c|c|c|c|c|c|c|}
\hline \multicolumn{7}{|c|}{$\mathrm{g} \mathrm{kg}^{-1}$} & \multicolumn{6}{|c|}{$\mathrm{mg} \mathrm{kg}^{-1}$} \\
\hline $\mathrm{N}$ & $\mathrm{K}_{2} \mathrm{O}$ & $\mathrm{Ca}$ & $\mathrm{Mg}$ & $\mathrm{S}$ & C & $\mathrm{P}_{2} \mathrm{O}_{5}$ & $\mathrm{Cu}$ & $\mathrm{Fe}$ & $\mathrm{Mn}$ & $\mathrm{Zn}$ & $\mathrm{Na}$ & B \\
\hline 1,5 & 0,6 & 1,9 & 0,5 & 0,6 & 32 & 1 & 88 & 13.490 & 280 & 237 & 1.079 & 180 \\
\hline \multicolumn{7}{|c|}{ C/N: 21} & \multicolumn{6}{|c|}{ pH: 6} \\
\hline
\end{tabular}

As águas utilizadas nas irrigações também foram caracterizadas (Tabela 03) de acordo com metodologia proposta por Malavolta et al. (1997). Deve-se destacar que essas são originárias do processo de tratamento do esgoto da cidade de Bauru-SP (ETE Candeia), e foram disponibilizadas pelo Departamento de Água e Esgoto de Bauru-SP.

Tabela 3 - Resultado da análise química das águas.

\begin{tabular}{cccccccc}
\hline AMOSTRA(S) & $\mathrm{N}$ & $\mathrm{P}$ & $\mathrm{K}$ & $\mathrm{Ca}$ & $\mathrm{Mg}$ & $\mathrm{S}$ & $\mathrm{Na}$ \\
& & & -------------- & $\mathrm{mg} \mathrm{L}^{-1}$ & ------------- & & \\
\hline Água de abastecimento & 8 & 0 & 12 & 18 & 2 & 4 & 26,10 \\
Água residuária & 73 & 5 & 14 & 6 & 3 & 15,1 & 72 \\
\hline
\end{tabular}

\section{Instalação do Experimento}

As sementes de pau viola foram fornecidas pelo viveiro onde foi realizado o experimento. Estas sementes foram colhidas quando os frutos iniciaram sua abertura espontânea e diretamente das árvoresmatrizes no município de Bauru/SP e municípios adjacentes, tendo sido respeitado sempre que possível, uma distância de 50-100m entre os indivíduos. Em seguida, os frutos ficaram amontoados alguns dias para iniciar sua decomposição e assim, despolpá-los manualmente em peneira sob água corrente. Para finalizar o processo, as sementes ficaram no sol para secagem. Essas apresentavam taxa de germinação abundante (mais de $80 \%$ ). Dados como a localização por GPS de cada árvorematriz, bem como o número de frutos gerado por cada indivíduo não foi disponibilizado pelo viveiro.

A semeadura foi primeiramente realizada em canteiro de areia, a qual é considerada substrato inerte e serve de sustentação para a plântula formada a partir da germinação da semente. Quando essas apresentaram altura de 3 a $7 \mathrm{~cm}$ e dois pares de folhas (51 dias após a semeadura), a sementeira foi umedecida, e as plantas foram arrancadas delicadamente, segurando pelo colo (região entre a raiz e o caule), e transplantadas em recipientes (tubetes) contendo os substratos (T1 a T5).

Os recipientes (tubetes) que receberam as mudas, já contendo o substrato, foram molhados. Foi aberto um orifício em cada tubete, com profundidade suficiente para acomodar as raízes. Quando necessário, as raízes foram podadas para reduzir o volume radicular, facilitando a acomodação da muda no recipiente. Por fim, as plântulas foram plantadas, preenchendo o orifício com substrato. A repicagem gerou 120 indivíduos identificados, que permaneceram durante 14 dias em casa de sombra (cobertura de tela de sombreamento de 50\%), para posteriormente ser realizada a rustificação e dar início as diferentes aplicações com águas de irrigação.

\section{Irrigação das mudas}

A irrigação da lâmina 1 (água de abastecimento) foi efetuada por sistema de micro aspersão, utilizando $30 \mathrm{~mm}$ de água por dia, por bandeja, dividida em 3 vezes ao dia. Os micros aspersores são do tipo fixo, com 1,25 m de distância entre cada. As plantas irrigadas com água residuária tiveram a irrigação iniciada 60 dias após a repicagem, sendo realizada $1 \mathrm{vez}$ ao dia, por meio de irrigador, utilizando a dosagem de $1.180 \mathrm{~mm}$ de água por dia, por badeja, até aos 180 dias, após o transplantio (DAT). A partir do dia 10 a irrigação passou a ser realizada 2 vezes ao dia (manhã e tarde), utilizando-se $3.540 \mathrm{~mm}$ de água por dia, por bandeja, no total, até ao final do experimento. 
Os tipos de irrigação foram diferentes devido ao viveiro já utilizar micro aspersores como forma de irrigação padrão, e não comportar a irrigação da água residuária que estava armazenada em tambores metálicos.

\section{Avaliações biométricas}

As medições dos parâmetros biométricos foram realizadas a cada 30 dias, a partir de 60 DAT, com medições de altura e diâmetro de coleto (paquímetro - valores expressos em milímetro), e contagem do número de folhas, realizando-se as devidas anotações de crescimento, mortalidade e percentual de mudas cultivadas. Foi verificado também se houve a incidências de pragas, doenças e plantas daninhas. O experimento foi encerrado aos 180 dias, quando as mudas já estavam estabelecidas e prontas para serem comercializadas.

Para altura e número de folhas, realizaram-se 5 avaliações: 60, 90, 120, 150 e 180 DAT. Para o diâmetro do coleto, realizou-se apenas 3 avaliações a partir dos 120 dias (120, 150 e 180 DAT), sendo que, anteriormente, os valores foram inferiores a $10 \mathrm{~mm}$.

Aos 180 DAT foi realizada ainda a pesagem da matéria fresca. As mudas foram divididas em parte aérea e raiz, devidamente identificadas e pesadas. Após $48 \mathrm{~h}$ em estufa a parte aérea e raiz foi pesada novamente.

Foi utilizado o Índice de Qualidade de Dickson (IQD) para avaliar a qualidade de mudas. Este índice é determinado em função da altura da parte aérea, do diâmetro de coleto e fitomassa seca total que é dada pela soma da fitomassa seca da parte aérea e a fitomassa seca das raízes, representada abaixo:

$$
I Q D=\frac{P M S T}{\frac{H}{D C}+\frac{P M S P A}{P M S R}}
$$

Em que:

$$
\begin{aligned}
& \text { PMST = Peso da massa seca total }(\mathrm{g}) \\
& (\mathrm{MSPA}+\mathrm{MSR}) ; \\
& \mathrm{H}=\text { Altura }(\mathrm{cm}) ; \\
& \text { DC = Diâmetro do coleto }(\mathrm{mm}) ; \\
& \text { PMSPA = Peso da massa seca da parte aé- } \\
& \text { rea }(\mathrm{g}) ; \\
& \text { PMSR = Peso da massa seca das raízes } \\
& (\mathrm{g}) .
\end{aligned}
$$

\section{Análise dos Dados}

Foram analisados percentualmente e comparativamente os valores médios dos diferentes tratamentos nas mudas cultivadas, tipo de substrato e irrigação, considerando o delineamento em parcelas subdivididas proposto. Os dados foram submetidos à análise estatística utilizando o programa AgroEstat (Barbosa; Maldonato Júnior, 2008). Os valores obtidos foram analisados pelo teste de Tukey, sendo considerados significativos quando $\mathrm{P} \leq 0,05$.

\section{RESULTADOS}

Os resultados obtidos para altura, número de folhas e diâmetro do coleto das plantas estão apresentados nas tabelas 4,5 e 6 .

Tabela 4 - Altura (mm) do pau viola com base em diferentes composições de substratos e lâmina de água.

\begin{tabular}{cccccc}
\hline \multirow{2}{*}{ Tratamentos $^{*}$} & $\mathbf{6 0}$ & $\mathbf{9 0}$ & $\mathbf{1 2 0}$ & $\mathbf{1 5 0}$ & $\mathbf{1 8 0}$ \\
\cline { 2 - 6 } & \multicolumn{5}{c}{ Dias após o transplantio } \\
\hline T1 & 28,50 & 34,75 & 54,83 & 70,45 & 74,66 \\
T2 & 30,70 & 41,91 & 70,02 & 81,02 & 84,52 \\
T3 & 23,50 & 36,00 & 65,37 & 77,25 & 81,41 \\
T4 & 27,83 & 40,54 & 65,00 & 75,70 & 79,79 \\
T5 & 25,50 & 37,40 & 56,43 & 72,97 & 80,75 \\
\hline Teste F & $1,70^{\mathrm{ns}}$ & $0,80^{\mathrm{ns}}$ & $3,89^{\mathrm{ns}}$ & $1,98^{\mathrm{ns}}$ & $1,54^{\mathrm{ns}}$ \\
DMS & 10,38 & 16,48 & 15,99 & 14,03 & 14,11 \\
\hline L1 & $26,30 \mathrm{a}$ & $31,98 \mathrm{~b}$ & $37,96 \mathrm{~b}$ & $47,11 \mathrm{~b}$ & $50,65 \mathrm{~b}$ \\
L2 & $28,13 \mathrm{a}$ & $44,26 \mathrm{a}$ & $86,70 \mathrm{a}$ & $103,85 \mathrm{a}$ & $109,81 \mathrm{a}$ \\
\hline Teste F & $2,50^{\mathrm{ns}}$ & $42,06^{* *}$ & $360,69^{* *}$ & $341,49^{* *}$ & $372,44^{* *}$ \\
DMS & 2,59 & 4,21 & 5,71 & 6,84 & 6,83 \\
Inter TxL & $1,90^{\mathrm{ns}}$ & $2,12^{\mathrm{ns}}$ & $1,84^{\mathrm{ns}}$ & $0,08^{\mathrm{ns}}$ & $0,10^{\mathrm{ns}}$ \\
\hline
\end{tabular}

Nota: Letras na coluna diferem de acordo com teste de Tukey 5\%. ** significativo ao nível de $1 \%$ de probabilidade (p <.01); * significativo ao nível de $5 \%$ de probabilidade $(.01=<\mathrm{p}<.05)$; ns não significativo (p >=.05). DMS: diferença mínima significativa; Inter TxL: Interação Tratamentos Principais e Secundários. T1: $100 \%$ SC; T2: 83,29\% SC e 16,71\% LEC; T3: 71,43\% SC e 28,57\% LEC; T4: 62,5\% SC e 37,5\% LEC; T5: 55,56\% SC e 44,44\% LEC; L1: água de abastecimento; L2: água residuária. 
Tabela 5 - Número de folhas de pau viola com base em diferentes composições de substratos e lâmina de água.

\begin{tabular}{cccccc}
\hline \multirow{2}{*}{ Tratamentos } & $\mathbf{6 0}$ & $\mathbf{9 0}$ & $\mathbf{1 2 0}$ & $\mathbf{1 5 0}$ & $\mathbf{1 8 0}$ \\
\cline { 2 - 6 } & \multicolumn{5}{c}{ Dias após o transplantio } \\
\hline T1 & 6,04 & 6,33 & $9,45 \mathrm{c}$ & $10,95 \mathrm{~b}$ & 12,33 \\
T2 & 4,79 & 8,00 & $12,16 \mathrm{a}$ & $13,70 \mathrm{a}$ & 14,72 \\
T3 & 4,54 & 7,50 & $10,83 \mathrm{abc}$ & $11,33 \mathrm{~b}$ & 12,33 \\
T4 & 4,91 & 7,66 & $10,58 \mathrm{bc}$ & $12,16 \mathrm{ab}$ & 13,87 \\
T5 & 4,54 & 7,83 & $10,95 \mathrm{ab}$ & $13,40 \mathrm{a}$ & 14,94 \\
\hline Teste F & $3,84^{\mathrm{ns}}$ & $3,02^{\mathrm{ns}}$ & $10,97^{* *}$ & $13,68^{* *}$ & $3,69^{\mathrm{ns}}$ \\
DMS & 1,55 & 1,85 & 1,42 & 1,61 & 3,2 \\
\hline L1 & $4,93 \mathrm{a}$ & $6,20 \mathrm{~b}$ & $8,90 \mathrm{~b}$ & $11,10 \mathrm{~b}$ & $11,15 \mathrm{~b}$ \\
L2 & $5,00 \mathrm{a}$ & $8,73 \mathrm{a}$ & $12,70 \mathrm{a}$ & $13,52 \mathrm{a}$ & $16,13 \mathrm{a}$ \\
\hline Teste F & $0,18^{\mathrm{ns}}$ & $48,13^{* *}$ & $58,67^{* *}$ & $18,16^{* *}$ & $37,85^{* *}$ \\
DMS & 0,35 & 0,81 & 1,1 & 1,26 & 1,8 \\
Inter TxI & $0,51^{\mathrm{ns}}$ & $1,22^{\mathrm{ns}}$ & $0,90^{\mathrm{ns}}$ & $1,08^{\mathrm{ns}}$ & $0,85^{\mathrm{ns}}$ \\
\hline
\end{tabular}

Nota: Letras na coluna diferem de acordo com teste de Tukey $5 \%$. ** significativo ao nível de $1 \%$ de probabilidade (p <.01); * significativo ao nível de $5 \%$ de probabilidade $(.01=<p<.05)$; ns não significativo ( $p>=.05)$. DMS: diferença mínima significativa; Inter TxL: Interação Tratamentos Principais e Secundários. T1: 100\% SC; T2: 83,29\% SC e 16,71\% LEC; T3: 71,43\% SC e 28,57\% LEC; T4: 62,5\% SC e 37,5\% LEC; T5: 55,56\% SC e 44,44\% LEC; L1: água de abastecimento; L2: água residuária.

Tabela 6 - Diâmetro de coleto $(\mathrm{mm})$ do pau viola com base em diferentes composições de substratos e lâmina de água.

\begin{tabular}{cccc}
\hline \multirow{2}{*}{ Tratamentos } & $\mathbf{1 2 0}$ & $\mathbf{1 5 0}$ & $\mathbf{1 8 0}$ \\
\cline { 2 - 4 } T1 & & Dias após o transplantio & $0,21 \mathrm{~b}$ \\
T2 & 0,16 & 0,19 & $0,27 \mathrm{a}$ \\
T3 & 0,21 & 0,23 & $0,24 \mathrm{ab}$ \\
T4 & 0,20 & 0,23 & $0,25 \mathrm{ab}$ \\
T5 & 0,20 & 0,21 & $0,25 \mathrm{ab}$ \\
\hline F & 0,16 & 0,21 & $3,48^{*}$ \\
L1 & $2,69^{\mathrm{ns}}$ & $2,95^{\mathrm{ns}}$ & 0,05 \\
\hline L2 & 0,06 & 0,06 & $0,16 \mathrm{~b}$ \\
F & $0,10 \mathrm{~b}$ & $0,12 \mathrm{~b}$ & $0,33 \mathrm{a}$ \\
\hline DMS & $0,28 \mathrm{a}$ & $0,31 \mathrm{a}$ & $113,44^{* *}$ \\
\end{tabular}

Nota: Letras na coluna diferem de acordo com teste de Tukey $5 \%$. ** significativo ao nível de $1 \%$ de probabilidade (p <.01); * significativo ao nível de $5 \%$ de probabilidade (.01 $=<\mathrm{p}<.05)$; ns não significativo ( $\mathrm{p}>=.05$ ). DMS: diferença mínima significativa; Inter TxL: Interação Tratamentos Principais e Secundários. T1: 100\% SC; T2: 83,29\% SC e 16,71\% LEC; T3: 71,43\% SC e 28,57\% LEC; T4: 62,5\% SC e 37,5\% LEC; T5: $55,56 \%$ SC e 44,44\% LEC; L1: água de abastecimento; L2: água residuária.

Ao final do experimento, aos 180 dias após o tratamento, as mudas foram removidas dos substratos, separando-se parte aérea e raiz, sendo essas pesadas e secadas para a determinação da matéria seca e do IQD das plantas (Tabela 07).

Tabela 7 - Matéria seca do pau viola com base em diferentes composições de substratos e lâmina de água.

\begin{tabular}{|c|c|c|c|c|}
\hline Tratamentos & MS total (g) & MS aérea (g) & MS raiz (g) & IDQ \\
\hline $\mathrm{T} 1$ & 21,50 & 9,16 & 12,33 & 0,60 \\
\hline $\mathbf{T 2}$ & 22,66 & 9,66 & 13,00 & 0,70 \\
\hline T3 & 22,50 & 9,16 & 13,33 & 0,65 \\
\hline T4 & 25,66 & 9,33 & 17,50 & 0,79 \\
\hline T5 & 22,83 & 9,66 & 13,16 & 0,68 \\
\hline $\mathbf{F}$ & $0,82^{\mathrm{ns}}$ & $0,79^{\mathrm{ns}}$ & $1,78^{\mathrm{ns}}$ & $1,28^{\mathrm{ns}}$ \\
\hline DMS & 8,43 & 1,38 & 7,56 & 0,31 \\
\hline L1 & $12,86 \mathrm{~b}$ & $6,20 \mathrm{~b}$ & $6,66 \mathrm{~b}$ & $0,38 \mathrm{~b}$ \\
\hline $\mathbf{L 2}$ & $33,20 \mathrm{a}$ & $12,60 \mathrm{a}$ & $21,06 \mathrm{a}$ & $0,98 \mathrm{a}$ \\
\hline $\mathbf{F}$ & $179,93^{* * *}$ & $418,91^{* *}$ & $124,42^{* *}$ & $158,86^{* *}$ \\
\hline DMS & 3,37 & 0,69 & 2,87 & 0,1 \\
\hline Inter IxL & $1,14^{\mathrm{ns}}$ & $0,16^{\mathrm{ns}}$ & $2,44^{\mathrm{ns}}$ & $1,48^{\mathrm{ns}}$ \\
\hline
\end{tabular}

Nota: Letras na coluna diferem de acordo com teste de Tukey 5\%. ** significativo ao nível de $1 \%$ de probabilidade (p <.01); * significativo ao nível de $5 \%$ de probabilidade $(.01=<\mathrm{p}<.05)$; ns não significativo ( $>>=.05$ ). DMS: diferença mínima significativa; MS: matéria seca; IQD: Índice de Qualidade de Dickson; Inter TxL: Interação Tratamentos Principais e Secundários. T1: 100\% SC; T2: 83,29\% SC e 16,71\% LEC; T3: 71,43\% SC e 28,57\% LEC; T4: 62,5\% SC e 37,5\% LEC; T5: 55,56\% SC e 44,44\% LEC; L1: água de abastecimento; L2: água residuária. 


\section{DISCUSSÃO}

Observou-se que os diferentes substratos, seja esse comercial, LEC ou mistura dos dois, não promoveram diferenças na altura das mudas de pau de viola durante as 5 épocas avaliadas, bem como na matéria seca da planta e no IQD. Entretanto, foi possível verificar que o LEC resultou em coleto de maior espessura e com maior número de folha já aos 120 DAT.

Segundo Vieira e Weber (2015), o rápido e melhor desenvolvimento de mudas é de grande interesse dos produtores de viveiros, uma vez que há aumento na quantidade de mudas produzidas em menor período, sem perdas na qualidade. Isso se torna uma vantagem no momento do plantio, já que mudas de melhor qualidade tendem a se desenvolver mais rápido e ter um melhor desenvolvimento no campo, além de contribuir para minimizar custos na produção.

Corroborando com o presente estudo, Abreu et al. (2017) verificaram que a espécie aroeira-pimenteira (Schinus terebinthifolia) obteve maiores médias de diâmetro do coleto nos tratamentos com $50 \%$ e $100 \%$ LEC. Isso pode ser explicado devido a espécies de crescimento relativamente rápido, como a aroeira-pimenteira, requererem grandes quantidades de nutrientes para seu crescimento e tendo uma melhor resposta à concentração de nutrientes no substrato, como o $\mathrm{N}$ e $\mathrm{P}$.

Marques et al. (2018) verificaram que o acréscimo da quantidade de LEC foi acompanhado pelo aumento das médias do diâmetro de coleto, com maior ênfase para as médias do tratamento que continham $40 \%$ LEC $+60 \%$ composto orgânico, sendo este o tratamento que rendeu as maiores médias para características morfológicas.

O maior diâmetro do coleto é interessante para as mudas nativas, pois o manejo para o plantio nas áreas definitivas ocorre através de manuseio dessa parte da planta. Dessa maneira, quanto mais espesso for esse coleto, mais fácil é o manejo, e menor o risco de danos à planta. Outro ponto a se destacar é a maior presença de folhas na planta. Isso significa maior área fotossintética da muda, favorecendo o rápido crescimento e estabelecimento da planta. Nesse contexto, pode-se inferir que o LEC promoveu um desenvolvimento da muda de pau viola mais interessante do que o SC.

Considerando-se a água de irrigação utilizada, observou-se que o uso de água residuária da Estação de Tratamento de Esgoto de Bauru/SP, apresentou efeito positivo significativo no desenvolvimento das mudas. Para todos os parâmetros avaliados, bem como em todos os tempos estudados, a água residuária promoveu incrementos nas mudas. Isso pode ser explicado a partir da composição da água de irrigação, que apresentava maiores teores de N, P, K, S e Na em relação a água de abastecimento (Tabela 3).

Esse comportamento também já havia sido determinado por outros autores que verificaram que a água residuária pode ser mais nutritiva que a água de abastecimento. Muraishi et al. (2010) observaram maiores altura para mudas de Ipê roxo (Tabebuia heptaphylla); Augusto et al. (2003) verificaram que mudas de Capixingui (Croton floribundus) e Copaíba (Copaifera langsdorffii) ficam mais vigorosas; Oliveira et al. (2012) avaliaram esse benefício em mudas de Sabiá (Mimosa caesalpiniifolia Benth) e Mororó (Bauhinia forficata Linn); Costa et al. (2012) observaram maior diâmetro do coleto da Timbaúba (Enterolobium contortisiliquum).

Neste contexto, pode-se destacar ainda o elevado IQD observado. De acordo com Delarmelina et al. (2014), para que as mudas tenham qualidade para ir à campo, o IQD deve ser de, no mínimo, 0,20. Nesse estudo, verificou-se que o IQD de mudas tratadas com águas residuárias foi de 0,98 , contra 0,38 obtido em mudas irrigadas com água de abastecimento.

Desta maneira, o experimento permite inferir que resíduos de tratamento de esgoto, seja o lodo, como a água residuária, que atualmente são considerados problemas para as cidades e com complicada disposição, podem ser utilizados para o cultivo de mudas nativas. Esse processo, além de melhorar o desenvolvimento da muda, poderá porventura reduzir os custos do viveirista com substratos comerciais, além de reduzir focos de poluição ambiental.

\section{CONCLUSÕES}

O LEC pode ser utilizado em sua forma pura, ou misturado com SC, melhorando a qualidade das mudas de pau viola, aumentando o diâmetro do coleto aos 180 dias após o transplantio, bem como o número de folhas entre 120 e 150 dias, após o transplantio. A utilização de água residuária da Estação de Tratamento de Esgoto de Bauru promoveu maior desenvolvimento das mudas em relação a água de abastecimento público, e deve ser utilizada preferencialmente para o cultivo de pau viola.

\section{AGRADECIMENTOS}

Ao Viveiro ACIFLORA e ao Departamento de Água e Esgoto de Bauru pelas parcerias durante a execução do projeto. Agradecemos as sugestões/correções dos dois revisores.

\section{REFERÊNCIAS BIBLIOGRÁFICAS}

Abreu AHM, Leles PSS, Melo LA, Oliveira RR, Ferreira DHAA. Caracterização e potencial de substratos formulados com biossólido na produção de mudas de Schinus 
terebinthifolius Raddi. e Handroanthus heptaphyllus (Vell.) Mattos. Ciência Florestal, v. 27, n. 4, p. 1179-1190, 2017.

Abreu AHM, Marzola LB, Melo LA, Leles PSS, Abel ELS, Alonso JM. Resíduos sólidos urbanos na produção de mudas de Lafoensia pacari. Revista Brasileira de Engenharia Agrícola e Ambiental, v. 21, n. 2, 2017.

Amaral WAN, Antiqueira LMOR, Horbach MA. Frutificação e ecologia da germinação de Citharexylum myrianthum Cham (Verbenaceae). Journal of Biotechnology and Biodiversity, v. 4, n. 3, p. 207-215, 2013.

Araújo EF, Arauco AMS, Lacerda JJJ, Ratke RF, Medeiros JC. Crescimento e balanço nutricional de mudas de Enterolobium contortsiliquum com aplicação de substratos orgânicos e água residuária. Pesquisa Florestal Brasileira, v. 36, n. 86, p. 169-177, 2016

Augusto DCC, Guerrini IA, Engel VL, Rousseau GX. Utilização de esgotos domésticos tratados através de um sistema biológico na produção de mudas de Croton floribundus Spreng. (Capixingui) e Copaifera langsdorfii. Desf. (Copaíba). Revista Árvore, v.27, n.3, p.335-342, 2003.

Barbosa JC, Maldonato Júnior W. AgroEstat - Sistema para análises estatísticas de ensaios agronômicos, versão 1.0. 2008 .

Brasil. Resolução CONAMA no 375, de 29 de agosto de 2006. Define critérios e procedimentos, para o uso agrícola de lodos de esgoto gerados em estações de tratamento de esgoto sanitário e seus produtos derivados, e dá outras providências. Disponível

em: <http://www2.mma.gov.br/port/conama/res/res06/res37506 .pdf>. Acesso em: 27 jun. 2020.

Costa MS, Alves SMC, Ferreira Neto M, Batista RO, Costa LLB, Oliveira WM. Produção de mudas de timbaúba sob diferentes concentrações de efluente doméstico tratado. Irriga, v. 01, n. 01, p. 408-422, 2012.

Cromer RN. Irrigation of radiata pine with wastewater: a review of the potential for tree growth and water renovation. Australian Forest, v. 43, p. 87-100, 1980.

Delarmelina WM, Caldeira MVW, Faria JCT, Gonçalves EOG, Rocha RLF. Diferentes substratos para a produção de mudas de Sesbania virgata. Floresta e Ambiente, v. 21, n. 2, p. 224-233, 2014.

Freire EA, Estrela MA, Lima VLA. Utilização de águas residuárias para fins da produção de mudas de espécies florestais. Revista Cultivar, 2010. Disponível em: < https://www.grupocultivar.com.br/noticias/artigoutilizacao-de-aguas-residuarias-para-fins-da-producao-demudas-de-especies-florestais>. Acesso: 04 junho 2020.

Lobo TF, Oliveira FC, Morgado BT, Siqueira MVBM. Diferentes Misturas de Substratos com Lodo de Esgoto Compostado Enriquecido e Substrato Comercial em Quaresmeira. Fronteiras: Journal of Social, Technological and Environmental Science, v. 7, n. 1, p.326-340, 2018.

Lustosa Filho JF, Nóbrega JCA, Nóbrega RSA, Dias BO, Amaral FHC, Amorim SPN. Influence of organic substrates on growth and nutrient contents of jatobá (Hymenaea stigonocarpa). African Journal of Agricultural Research, v. 10, n. 26 , p. 2544-2552, 2015

Malavolta E, Vitti GC, Oliveira SA. Avaliação do estado nutricional das plantas: Princípios, métodos e técnicas de avaliação do estado nutricional. 2. ed. Piracicaba: Potafos, 1997. 319p.

Marques ARF, Oliveira VS, Boligon AA, Vestena S. Produção e qualidade de mudas de Psidium cattleianum var. Cattleianum sabine (Myrtaceae) em diferentes substratos. Acta Biológica Catarinense, v. 5, n. 1, p. 5-13, 2018.

Morgado BT, Olher I, Timo TPC, Rossi MN, Lobo TF, Siqueira MVBM. Growth of Cecropia hololeuca in water blades and substrates formulated with sewage sludge. Revista Ciências Agrárias, v. 63, p.1-10, 2020.

Muraishi RI, Galbiatti JÁ, Nobile FO, Barbosa JC. Compostos orgânicos como substratos na formação de mudas de ipêamarelo (Tabebuia chrysotricha (Mart. Ex. Dc.) standl) irrigadas com água residuária. Engenharia Agrícola, v. 30, n. 6, p. 1081-1088, 2010.

Oliveira JF, Alves SMC, Batista RO, Costa MS, Queiroz JL, Lima VIA. Avaliação de mudas de sabiá e mororó fertirrigadas com esgoto doméstico tratado. Revista Agropecuária Científica no Semiárido, v. 9, n. 4, p. 46-52, 2012.

Paez DRM. Utilização do lodo de esgoto na produção de mudas e no cultivo do eucalipto (Eucalyptus spp). 2011. 44 f. Monografia (Bacharel em Engenharia Florestal) - Instituto de florestas da Universidade Federal Rural do Rio de Janeiro, Seropédica, 2011.

Rebouças JRL, Neto MF, Dias NS, Gomes JWS, Gurgel GCS, Queiroz ISR. Qualidade de mudas de sabiá irrigadas com efluente doméstico. Floresta, v. 48, n. 2, p. 173-182, 2018.

Santana LO, Araujo FM, Timo TFC, Lobo TF, Siqueira MVBM. Desenvolvimento de mudas de dedaleiro (Lafoensia pacari A.St-Hil.) mediante diferentes substratos e lâminas de irrigação. Revista Instituto Florestal, v.31, n.2, p.147-156, 2019.

Santos EVF, Kunz, SH, Caldeira MVW, Azevedo CHS Rangel OJP. Características químicas de substratos formulados com lodo de esgoto para produção de mudas florestais. Revista Brasileira de Engenharia Agrícola e Ambiental, v.18, p.971-979, 2014.

Souza VC. Citharexylum myrianthum Cham. Reflora, 2014 Disponível <http://floradobrasil.jbrj.gov.br/jabot/floradobrasil/FB1513 6>. Acesso em 20 ago. 2018.

Trazzi PA, Caldeira MVW, Reis EF, Silva AG. Produção de mudas de Tectona grandis em substratos formulados com biossólido. Cerne, v. 20, n. 2, p. 293-302, 2014.

Trazzi PA, Caldeira MVW, Passos RR, Gonçalves EO Substratos de origem orgânica para produção de mudas de teca (Tectona grandis Linn. F.). Ciência Florestal, v. 23, n. 3, p. 401-409, 2013.

Trigueiro RM, Guerrini IA. Utilização de lodo de esgoto na produção de mudas de Aroreira-pimenteira. Revista Árvore, v. 38, n. 4 , p. $657-665,2014$

Vieira CR, Weber OLS. Avaliação de substratos na produção de mudas de jatobá. Revista de Ciências Ambientais, v. 9, n. 2, p. 145-158, 2015 